\title{
Processo de Implantação de Cursos de Pós-Graduação Lato Sensu a Distância: um estudo de caso
}

\author{
Sidnei Renato Silveira, UniRitter, sidnei@uniritter.edu.br \\ Clarissa Tarragô Candotti, UniRitter, clarissa@uniritter.edu.br \\ Marlise Geller, ULBRA, marlise.geller@gmail.com \\ Sílvia de Castro Bertagnolli, UniRitter, silviacb@uniritter.edu.br
}

\section{Resumo}

Este artigo apresenta um estudo de caso para implantação de cursos de Pós-graduação Lato Sensu a distância. Ao longo da elaboração do planejamento estratégico, buscamos articular premissas teóricas que consolidassem na prática o plano de marketing, a gestão de pessoas e o plano financeiro, originando um curso de especialização na modalidade a distância voltado as expectativas de alunos, professores e da Instituição proponente.

Palavras-Chave: Educação a Distância, Gestão de espaços de EaD, Planejamento Estratégico.

\section{Process of Introduction of Distance Postgraduate Courses: a study of} case

\section{Abstract}

This paper presents a study of case to introduce distance postgraduate courses. During the preparation of strategic planning, seek to articulate the theoretical premise that consolidate in practice the marketing plan, people management and the financial plan, resulting in a plan of distance postgraduate courses back the expectations of students, teachers and the institution that proposes.

Keywords: Distance Education, Distance Education Management, Business Plan

\section{Introdução}

Este artigo apresenta o processo para elaboração de uma proposta de curso de Pós-Graduação Lato Sensu a distância, focado na formação de profissionais para atuarem em cursos na modalidade de EaD (Educação a Distância). Parte-se do pressuposto de que, para a implantação de cursos a distância, é necessária a criação de um planejamento estratégico, dentro do contexto da gestão de espaços de EaD. Esta gestão envolve desde a organização e acompanhamento de cursos e núcleos até o suporte prestado para o atendimento aos alunos. Não se pode esquecer, também, da avaliação dos serviços, que deve acompanhar todo o processo.

Segundo o Ministério da Educação, os cursos de pós-graduação Lato Sensu compreendem programas de especialização e incluem os cursos designados como MBA - Master in Business Administration. São cursos que possuem duração mínima de 360 horas, abertos a candidatos diplomados em cursos superiores, que atendam às exigências das instituições de ensino (Ministério da Educação, 2009).

Neste sentido, o artigo está estruturado da seguinte forma: a seção 1 apresenta as etapas necessárias para a construção do planejamento estratégico de cursos a distância. A seção 2 apresenta um estudo de caso, contemplando as etapas 
desenvolvidas para a proposta de implantação de um curso de pós-graduação Lato Sensu a distância. A seção 3 explora o Projeto Pedagógico do Curso. Encerrando o artigo, destaca-se a importância desta modalidade de ensino na formação continuada no país.

\section{Etapas para Planejamento}

Para implantar um curso, incluindo cursos a distância, deve-se elaborar um planejamento estratégico e/ou um plano de negócios, abordando diversas áreas: posicionamento estratégico, gestão de pessoas, marketing e planejamento financeiro. Segundo Colombo (2004), "o planejamento estratégico é um importante instrumento de gestão que auxilia, consideravelmente, o administrador educacional em seu processo decisório na busca de resultados mais efetivos e competitivos para a instituição de ensino" (p. 17).

"O planejamento consiste na identificação, na análise e na estruturação dos propósitos da instituição rumo ao que se pretende alcançar, levando em consideração suas políticas e recursos disponíveis. Contempla indagações no âmbito do que fazer, como, por que, quando, por quem e onde" (Colombo, 2004, p. 17). Estas indagações podem ser respondidas através de um quadro, onde podem ser apresentadas as metas que se pretende alcançar:

Quadro 1 - Metas do planejamento

\begin{tabular}{|l|l|l|l|l|l|}
\hline Meta & Como? & Por quê? & Quando & Por quem? & Onde? \\
\hline & & & & & \\
\hline
\end{tabular}

O planejamento pode ser dividido em três níveis: estratégico, tático e operacional (Martins, 2007):

- Estratégico: formado pela alta gerência, que determina os macroobjetivos da organização e elabora as estratégias a serem adotadas;

- Tático: envolve as pessoas que interpretam o planejamento estratégico e o transformam em planos específicos para cada área da organização;

- Operacional: grupo de pessoas que colocará em prática as atividades planejadas (execução).

Thompson e Strickland (2000) colocam que a estratégia consiste no conjunto de mudanças competitivas para atingir o melhor desempenho de uma organização. Ansoff e McDonnell (1993) colocam que estratégia é "um conjunto de regras de tomada de decisão para orientação do comportamento de uma organização" (p. 70).

Neste contexto, a análise estratégica é uma ferramenta que permite definir os rumos de uma Instituição, analisando possibilidades futuras (Costa, 2002). A análise estratégica é importante para a visão do futuro, permitindo o posicionamento da organização em uma perspectiva global. Segundo este mesmo autor, a visão estratégica consiste em "...desenvolver a capacidade de olhar, criticamente, o presente a partir do futuro e não o futuro com os olhos do presente. Esse é o grande desafio a vencer" (Costa, 2002, p. 13). 
Marcial e Grumbach (2002) apresentam alguns benefícios da elaboração do planejamento estratégico:

- Melhorar a compreensão dos ambientes interno e externo;

- Permitir aos gestores lidar de forma mais adequada com as incertezas;

- Facilitar a criação de redes de troca de informações entre as diversas áreas da organização;

- Propiciar uma visão global do ambiente e suas interligações;

- Auxiliar no desenvolvimento da criatividade organizacional;

- Auxiliar na identificação de novas oportunidades de negócios.

O planejamento estratégico envolve, inicialmente, uma fase de diagnóstico. Após esta fase, devem ser elaborados os planos de marketing, gestão de pessoas e financeiro, como apresentam as próximas seções.

\subsection{Plano de Marketing}

Kotler (apud Martins 2007, p. 66) afirma que marketing é “...um processo administrativo e social pelo qual indivíduos e grupos obtêm o que necessitam e desejam, por meio da criação, oferta e troca de produtos e valor com os outros". Martins (2007) coloca que, a principal função do marketing é conduzir a estratégia corporativa e fazer com que sejam cumpridas as promessas da organização.

Segundo Certo (2005, p. 174), o mix de marketing é composto de "produto, preço, promoção e canais de distribuição", os quatro P's do marketing: produto, preço, promoção e praça, descritos por Martins (2007) como:

- O produto deve ser entendido como um bem material (tangível) ou imaterial (intangível) que é oferecido a um mercado, com o objetivo de satisfazer as necessidades de consumo. É um objeto de desejo ou a experiência a ser oferecida ao consumidor. No caso de uma organização educacional, o produto é, na verdade, um serviço intangível;

- A praça é o ponto de venda que a empresa possui para fazer seus produtos ou serviços chegarem até seus clientes. Considerando a $\mathrm{EaD}$, a praça pode envolver a Internet e os pólos de apoio presencial, além de outros aspectos;

- Promoção é o conjunto de ações que uma organização utiliza para divulgar e convencer os interessados a consumirem seus produtos ou serviços;

- Preço envolve a política de preços, descontos e formas de pagamento oferecidas.

O plano de marketing deve descrever as características dos produtos que serão produzidos e/ou ofertados pela organização, critérios para formação do preço, estratégias de promoção e praça. Além disso, o plano de marketing deve traçar um comparativo da organização com suas principais concorrentes, a partir da análise dos 4 P's. Esta análise deve evidenciar as principais características dos produtos, preço, promoção e praça, tendo-se em vista a definição do posicionamento da organização.

A análise deste 4 P's é orientada pelas variáveis que compõem a oferta de serviços e produtos da organização. Em contrapartida a este modelo, existem os 
sistemas orientados a clientes que procuram, primeiramente, identificar e classificar a forma como os clientes irão se posicionar frente ao que está sendo ofertado. Após esta identificação, a organização analisa e avalia o comportamento e as atitudes do consumidor, para definir a estratégia que será implementada (Martins, 2007).

Considerando as etapas do planejamento foi elaborada a próxima seção que aborda o plano de gestão de pessoas.

\subsection{Plano de Gestão de Pessoas}

A gestão de pessoas inicia-se com o recrutamento de pessoal. Segundo Chiavenato, recrutamento envolve "todos os esforços da empresa em trazer para si novos colaboradores" (1994, p. 79). O recrutamento é uma ação externa da organização para influenciar o mercado de recursos humanos e dele obter candidatos de que necessita para suprir suas lacunas. Após o recrutamento, a análise dos candidatos passa por duas etapas, que caracterizam: 1) triagem - uma pré-seleção, visando identificar os candidatos aptos a participarem do processo seletivo; 2) seleção de pessoal - análise comparativa do perfil dos candidatos com as características desejadas e escolha dos candidatos (Chiavenato, 1994).

O plano de gestão de pessoas deve prever as ações necessárias para o recrutamento, triagem, seleção e integração de pessoal. Além disso, deve estabelecer o perfil desejado pela empresa, os cargos existentes e suas funções, remuneração e benefícios, avaliação de desempenho e um plano de capacitação constante da equipe.

Para Rocha-Pinto et. al. (2006), atualmente faz-se necessária a implantação de uma gestão flexibilizada de pessoas. Neste modelo os funcionários podem participar das decisões, exercer controle e compartilhar poder. Para que esta gestão ocorra na prática, é preciso que os funcionários trabalhem em equipe, com ampla e intensa cooperação. Este modelo de gestão flexibilizada se opõe ao modelo tradicional, autocrático, onde basta ordenar o que cada indivíduo da organização deve fazer. Na gestão flexibilizada deve-se motivar o indivíduo a realizar suas tarefas e inovar.

No caso de planejamentos voltados a organizações educacionais, especificamente em se tratando de $\mathrm{EaD}$, o plano de gestão de pessoas deve contemplar estratégicas de capacitação (formação de professores, tutores e funcionários técnicoadministrativos) e estratégias ligadas à remuneração e benefícios extras.

Além disso, o plano de gestão de pessoas deve prever os recursos humanos necessários para implantação de uma estrutura voltada à EaD, tais como a criação de Núcleos de Educação a Distância.

Outro planejamento realizado, com base nas etapas de planejamento, foi o financeiro, como descrito a seguir.

\subsection{Planejamento financeiro}

Certo (2005) destaca que o plano financeiro permite construir uma proposta de sustentabilidade da organização. No contexto do planejamento financeiro, destaca-se a importância do ponto de equilíbrio, que representa o nível de vendas que cobre todos os 
custos de investimento de um projeto. Para calcular o ponto de equilíbrio é preciso que se obtenham três valores:

1) preço de venda por unidade do produto (PV);

2) valor total dos custos fixos (CF); e

3) custos variáveis por unidade produzida (CV).

Os custos fixos são os que não mudam, independentemente do número de produtos produzidos. Contextualizando com a realidade de uma organização educacional, pode-se exemplificar que os custos fixos são os salários dos diretores e funcionários administrativos e custos que envolvem a manutenção dos laboratórios de informática.

Os custos variáveis podem ser exemplificados pela carga horária dos professores e tutores, já que a mesma varia de acordo com o número de alunos efetivamente matriculados. O cálculo do ponto de equilíbrio é a divisão dos custos fixos pela diferença entre o preço de venda e os custos variáveis (Certo, 2005).

No caso de cursos de EaD, deve-se considerar que a taxa de evasão é maior do que em cursos presenciais, o que eleva o ponto de equilíbrio.

A próxima seção apresenta alguns detalhes do planejamento do curso proposto, bem como alguns aspectos relacionados ao Projeto Pedagógico do Curso.

\section{Planejamento do Curso Proposto}

Elaborou-se uma proposta de curso de Pós-graduação Lato Sensu em Didática e Planejamento para Educação a Distância. Entre os objetivos do curso, pretende-se:

- qualificar profissionais de nível superior (Bacharéis e Licenciados) para a apropriação de ferramentas e metodologias visando a implantação de espaços de ensino e aprendizagem para $\mathrm{EaD}$;

- promover espaços de discussão sobre a modalidade de EaD, pautados em premissas legais, tecnológicas e pedagógicas, articulados ao perfil interdisciplinar dos profissionais envolvidos;

- (re)construir conhecimentos teórico-práticos para fomentar aplicações relevantes em ensino e pesquisa na área de $\mathrm{EaD}$, que possam contribuir com a sociedade.

As próximas seções apresentam as etapas do planejamento deste curso, bem como alguns aspetos relacionados ao seu projeto pedagógico.

\subsection{Planejamento Estratégico}

Inicialmente desenvolveu-se o planejamento estratégico para implantação deste curso, contemplando marketing, gestão de pessoas e a área financeira.

O planejamento estratégico iniciou através de um diagnóstico estratégico, envolvendo os aspectos externo (ameaças e oportunidades) e interno (potencialidades e fragilidades). As ameaças e oportunidades devem ser analisadas de acordo com a 
conjuntura regional, a partir de um levantamento dos cursos de EaD disponíveis na região. O diagnóstico interno envolve um olhar mais crítico da própria Instituição: "Quais são nossas potencialidades e fragilidades?".

Após o diagnóstico, definiram-se as aspirações e desejos organizacionais, buscando respostas para as seguintes perguntas: Onde estamos? Aonde queremos chegar? Como vamos chegar lá? Além disso, elencaram-se os diferenciais competitivos da organização e definiram-se a missão e a visão da mesma.

A missão e a visão são os alicerces de uma organização. Segundo Costa (2002), visão é "um conceito operacional muito preciso que procura descrever a auto-imagem da organização: como ela se vê, ou melhor, como ela gostaria de se ver no futuro" (p. 35). Cabe destacar que a visão não deve ser algo inatingível, ou seja, deve ser uma realidade futura possível. Todos os integrantes da organização devem conhecer e acreditar na visão e precisam fazer parte de um grupo sintonizado com a visão da instituição.

Com relação à missão, Costa (2002) coloca que "A formulação da missão pretende responder a perguntas como: qual a necessidade básica que a organização pretende suprir? Que diferença faz, para o mundo externo, ela existir ou não? Para que serve? Qual a motivação básica que inspirou seus fundadores? Por que surgiu?” (p. 36). Neste sentido, entende-se que a missão é a razão da existência da organização. Para Certo (2005), a missão é "uma declaração muito ampla da diretriz organizacional". A missão deve definir os rumos da organização, concentrando os esforços em uma direção comum. Bangs Jr. (1999) afirma que a declaração de missão deve sugerir a pergunta "Qual deveria ser o nosso negócio", mesmo que ele não reflita o estágio atual da organização, ou seja, a missão deve ter um foco no futuro.

No caso do planejamento do curso proposto, a Instituição já possuía sua missão e visão. Coube à equipe de planejamento, alinhar a missão e a visão do curso proposto com as institucionais.

\subsection{Plano de Marketing}

Concluindo-se a etapa que envolve o diagnóstico estratégico, passou-se para o plano de marketing. Este plano foi iniciado pela análise dos $4 \mathrm{P}^{\prime}$ s da própria instituição onde o curso será ofertado. Posteriormente realizou-se a análise dos 4 P's dos principais concorrentes. O Quadro 2 apresenta a análise dos 4 P’s da instituição onde o referido curso será implantado.

Quadro 2 - Análise dos 4 P's

\begin{tabular}{|c|c|}
\hline Produto & Preço \\
\hline $\begin{array}{c}\text { - Instituição tradicional, com mais de 35 anos de existência } \\
\text { - Excelente clima organizacional }\end{array}$ & $\begin{array}{c}\text { - a instituição não tem fins lucrativos, } \\
\text { mas não é filantrópica (o que reduz } \\
\text { alguns incentivos fiscais) }\end{array}$ \\
$\begin{array}{c}\text { - Processo de auto-avaliação consistente, que reforça os pontos } \\
\text { positivos e estabelece ações corretivas para os pontos negativos } \\
\text { detectados }\end{array}$ & $\begin{array}{c}\text { - Existem bolsas de Monitoria, } \\
\text { Iniciação Científica e Extensão }\end{array}$ \\
$\begin{array}{c}\text { - produção de livros didáticos através da editora da Instituição } \\
\text { - Projeto Pedagógico (privilegia a formação de cidadãos éticos } \\
\text { e a excelência do ensino, destacando-se a indissociabilidade } \\
\text { entre ensino, pesquisa e extensão) }\end{array}$ & $\begin{array}{c}\text { para os alunos atuarem na Instituição } \\
\text { - Crédito Educativo Federal (FIES) }\end{array}$ \\
\hline
\end{tabular}




\begin{tabular}{|c|c|}
\hline $\begin{array}{c}\text { - Titulação e experiência do Corpo Docente } \\
\text { - Investimento na qualificação do Corpo Docente } \\
\text { - Infraestrutura física e tecnológica } \\
\text { - Permanente atualização tecnológica } \\
\text { - Currículos dos cursos em constante atualização } \\
\text { - Foco na excelência } \\
\text { - Cursos com avaliações externas positivas (Guia do Estudante } \\
\text { da Editora Abril e Ministério da Educação - processos de } \\
\text { reconhecimento, renovação de reconhecimento, ENADE, etc) } \\
\text { - Investimento em projetos de pesquisa e projetos } \\
\text { extensionistas } \\
\text { - Inserção na comunidade do entorno }\end{array}$ & \\
\hline Promoção & Praça (Disponibilidade) \\
\hline $\begin{array}{c}\text { - Assessoria de Comunicação Social integrada } \\
\text { - Campanhas de Marketing } \\
\text { - Site } \\
\text { - Revista Conexão } \\
\text { - Boletins Informativos dos Cursos }\end{array}$ & $\begin{array}{l}\text { - localização privilegiada em POA, } \\
\text { mas com difícil acesso via transporte } \\
\text { coletivo } \\
\text { - horário de funcionamento (não são } \\
\text { realizadas atividades nas sextas-feiras } \\
\text { à noite e durante os sábados) } \\
\text { - Atividades realizadas via Internet, } \\
\text { nas disciplinas semipresenciais (EaD) }\end{array}$ \\
\hline
\end{tabular}

Cabe ressaltar que as estratégias de divulgação devem estar alinhadas com o trabalho pedagógico realizado e devem ser acompanhadas pela equipe de planejamento do curso, juntamente com a Assessoria de Comunicação da Instituição.

\subsection{Plano de Gestão de Pessoas}

O plano de gestão de pessoas previu o desenvolvimento de atividades voltadas à formação de docentes e tutores, além de atividades para preparação e aprimoramento do corpo técnico-administrativo já existente na Instituição.

No contexto dos recursos humanos, Rocha-Pinto (et. al., 2006) coloca que competência "está relacionada à pessoa - seus conhecimentos, habilidades e atitudes e à tarefa, associada a resultados" (p. 36). De acordo com este conceito, para a realização das atividades propostas, acredita-se que os integrantes de cursos de pós-graduação a distância devem possuir as seguintes competências básicas:

- Formação acadêmica compatível com a tarefa a ser desempenhada;

- Habilidade para solucionar problemas, sejam de ordem administrativa e/ou didático-pedagógica, visando a existência de um ambiente propício para os processos de ensino e de aprendizagem;

- Facilidade de comunicação através de ferramentas tecnológicas, principalmente no que diz respeito à utilização de ambientes virtuais de aprendizagem;

- Estarem em constante processo de aprendizado, participando das atividades de formação pedagógica de docentes e tutores e das atividades de qualificação do corpo técnico-administrativo. 
No planejamento do referido curso, previu-se a contratação de professores (conteudistas), tutores, equipe de suporte tecnológico e equipe para produção do material didático. Caso a instituição já conte com algum destes profissionais, pode-se definir quais formarão a equipe necessária.

\subsection{Plano Financeiro}

O plano financeiro deve prever o investimento necessário para a preparação dos conteúdos, além dos encargos necessários para a contratação de docentes, tutores e funcionários. Acredita-se que, para um melhor desempenho, as atividades dos tutores devam ser acompanhadas por docentes. Um ponto importante do plano financeiro é a preocupação com a evasão, tendo-se em vista que os cursos a distância possuam uma taxa de evasão maior do que os presenciais.

\section{Projeto Pedagógico do Curso}

Uma das especificações necessárias para a construção do Projeto Pedagógico do Curso é a definição dos módulos e dos recursos que serão empregados. Nesse momento, surgiu a preocupação com o desenvolvimento do material educacional que será utilizado, uma vez que, por ser um curso a distância, entende-se que há maior necessidade de adotar estratégias de ensino e de aprendizagem que mantenham os alunos motivados para aprender durante o curso.

Conforme Santos (apud Avenburg, 2003), o sucesso de qualquer iniciativa no campo da educação a distância tem como base três componentes principais: a qualidade do sistema de tutoria e acompanhamento, o engajamento efetivo dos alunos na dinâmica proposta e a natureza do material didático empregado.

Ao se planejar um material didático para $\mathrm{EaD}$ deve-se levar em consideração que ele é um importante canal de comunicação com o aluno, confundindo-se muitas vezes com o próprio curso. É necessário também considerar a relação entre o objetivo pretendido e os meios para alcançá-los, a relação entre a situação problema e os meios para sua superação (Averbug, 2003). O uso da tecnologia pela tecnologia não garante que se atinjam objetivos propostos, o diferencial está no planejamento pedagógico em que esses recursos estão inseridos (Torrezan e Behar, 2009). Assim, entende-se que, ao planejar os materiais educacionais para o curso a distância, faz-se necessário levar em consideração os conceitos de Design Instrucional, garantindo que a escolha do tipo de recurso empregado na elaboração dos materiais esteja em harmonia com os objetivos pretendidos para cada módulo do curso.

A evolução das tecnologias de informação e comunicação viabilizam novas abordagens para a Educação a Distância, especialmente pela possibilidade de interação entre alunos e professores por meio de ambientes virtuais de aprendizagem e o uso de materiais educacionais digitais, que possibilitam que conteúdos sejam abordados na forma de imagens digitais, vídeos, hipertextos, animações, simulações, objetos de aprendizagem, páginas web, entre outros (Torrezan e Behar, 2009). Assim, além do material impresso, os cursos de EaD dispõem também de materiais que usam outras linguagens midiáticas para se comunicar com os alunos, cada uma com suas próprias características pedagógicas. Para a criação de cursos a distância, acredita-se que é valioso tentar usar a combinação de todas as mídias, veiculadas pelas tecnologias mais 
convenientes, de modo que os alunos aproveitem os benefícios pedagógicos de cada uma delas (Moore e Kearsley, 2007).

Conforme Torrezzan e Behar (2009), a construção de materiais educacionais digitais leva em consideração fatores técnicos, gráficos e pedagógicos. $\mathrm{O}$ indicado é que esses três elementos sejam concomitantemente construídos por uma equipe interdisciplinar. Dessa forma, para a criação dos materiais educacionais digitais para o curso a distância, vê-se necessário, além da aquisição de equipamentos e software apropriados para o seu desenvolvimento, o trabalho especializado de profissionais de diversas áreas, como informática, comunicação, design gráfico e design pedagógico.

O UniRitter está investindo na construção de um estúdio para a construção de vídeos e gravação de áudios. Já foi adquirido o software para produção e edição de vídeos. Com o decorrer do tempo e oferecendo capacitação apropriada aos docentes, acredita-se que alguns materiais podem ser desenvolvidos pelos próprios docentes, como a construção de hipertexto e vídeos tutoriais. Outros materiais mais complexos deverão sempre passar por um trabalho em equipe.

Cabe ressaltar que uma das dificuldades encontradas para a implantação de cursos a distância é a criação de materiais educacionais que usem diferentes mídias. Neste contexto, os docentes têm que contar com o apoio de uma equipe interdisciplinar, demandando muito mais tempo, esforço e custos para a sua elaboração em comparação com a situação em que os docentes usam apenas a linguagem textual, o que possibilita que criem seu próprio material, geralmente, sem a necessidade de envolver terceiros.

Outro elemento fundamental para a EaD é o uso dos AVAs (Ambientes Virtuais de Aprendizagem), pois o ambiente deve viabilizar a comunicação dos envolvidos no processo de construção do conhecimento. Eles são essenciais, porque ampliam as possibilidades de interação entre aluno e professor, e permitem a organização das idéias, do conhecimento e oportunizam ao aluno uma maior autonomia com relação a sua aprendizagem (Mehlecke e Tarouco, 2003).

$\mathrm{Na}$ literatura encontram-se disponíveis vários AVAs como, por exemplo: Moodle, AulaNet, TelEduc, Dokeos e NAVi, entre outros. Porém, acredita-se que o AVA ideal é aquele que possui um conjunto diversificado de ferramentas que promovam a comunicação tanto assíncrona e síncrona. Além disso, o AVA deve oportunizar o desenvolvimento de atividades em grupo e colaborativas. Desse modo, percebeu-se que o ambiente Moodle seria o mais adequado à realidade do curso de Pós-graduação Lato Sensu descrito previamente.

Em linhas gerais, pode-se afirmar que o Moodle encontra-se organizado em 5 módulos (Bertagnolli, Fontanive e Silva, 2008):

1) o módulo de administração que possibilita o gerenciamento do sistema;

2) o módulo de atividades que disponibiliza as ferramentas de comunicação (fórum de discussões e o chat), as ferramentas de avaliação (pesquisa de opinião, questionário ou mini-teste, tarefas e trabalhos com revisão) e as ferramentas complementares (glossários, diários, importação e compartilhamento de conteúdos);

3) módulo meus cursos, responsável pela disponibilização da estrutura de cada curso no ambiente;

4) módulo calendário, que permite o agendamento de eventos do curso pelo aluno ou professor; 
5) módulo de participante (com registros de acesso e perfil de cada usuário registrado).

Ao analisar estes módulos percebe-se que o material didático poderá ser organizado de diversos modos, utilizando-se diferentes ferramentas.

Neste contexto, identifica-se que um dos desafios será a articulação do material didático com o AVA, ou seja, qual ferramenta será utilizada para explorar os vídeos, os recursos de hipertextos, as animações elaboradas, as páginas web, os blogs, as páginas wiki e os objetos de aprendizagem, visto que o ambiente disponibiliza várias ferramentas.

Pretende-se realizar um estudo analítico das ferramentas, de modo a mapear a ferramenta e o recurso de aprendizagem/comunicação que poderá ser adotado pelos professores, adequando o material elaborado com as atividades propostas.

\section{Considerações Finais}

Pretendeu-se, com esse artigo, colocar em discussão as etapas necessárias para a construção do planejamento estratégico para implantação de cursos de pós-graduação Lato Sensu a distância. Além de serem realizadas as etapas previstas (diagnóstico estratégico e planos de marketing, gestão de pessoas e financeiro), também elaborou-se o projeto pedagógico do curso.

Objetivando resolver uma das principais preocupações do processo de implantação do curso, a equipe vem elaborando e reavaliando os materiais didáticos multimídia até o momento desenvolvidos.

Acredita-se que a Educação a Distância, especialmente no contexto do Lato Sensu, abre um vasto campo de possibilidades para adultos já graduados, potencializando a permanência de alunos em um processo de formação continuada e a inserção de diferentes camadas sociais junto a Pós-Graduação no país.

\section{Referências}

ANSOFF, H. Igor; McDONNELL, Edward J. Implantando a Administração Estratégica. São Paulo: Atlas, 1993.

AVERBUG, Regina. Material didático impresso para educação a distância: tecendo um novo olhar. Revista Digital da CVA-RICESU. Colabor@. vol.2 n5 setembro 2003. Disponível em < http://www.ricesu.com.br/colabora/n5/artigos/n_5/id02.php >. Acesso em 10 ago, 2009.

BERTAGNOLLI, Silvia de Castro; FONTANIVE,M Mário Furtado; SILVA, Angela Maria. Customizando o Moodle para Criação de uma Comunidade de Aprendizagem em Ambiente Virtual para o Curso de Design. IV SEPesq - Semana de Extensão, Pesquisa e Pós-Graduação do UniRitter. 2008.

CERTO, Samuel C. et al. Administração Estratégica: planejamento e implantação da estratégia. São Paulo: Pearson Education do Brasil, 2005.

CHIAVENATO, Idalberto. Gerenciando Pessoas: o passo decisivo para a administração participativa. 3. ed. São Paulo: Makron Books, 1994. 
COLOMBO, Sônia Simões. Gestão Educacional: uma nova visão. Porto Alegre: Artmed, 2004.

COSTA, Eliezer Arantes. Gestão Estratégica. São Paulo: Saraiva, 2002.

MARCIAL, Elaine Coutinho; GRUMBACH, Raul José dos Santos. Cenários Prospectivos: como construir um futuro melhor. Rio de Janeiro: FGV, 2002.

MARTINS, Marcos Amancio P. Gestão Educacional: Planejamento Estratégico e Marketing. Rio de Janeiro: Brasport, 2007.

MEHLECKE, Querte Terezinha Conzi; TAROUCO, Liane Margarida Rockenbach. Ambientes de Suporte para Educação a Distância: a mediação para aprendizagem cooperativa. Revista Novas Tecnologias na Educação, v. 1, n. 1, Fevereiro, 2003. Disponível

em:

$<$ http://www.cinted.ufrgs.br/renote/fev2003/artigos/querte_ambientes.pdf > . Acesso em: maio, 2007.

MINISTÉRIO DA EDUCAÇÃO. Resolução CNE/CES n¹ de 03 de abril de 2001. Disponível em: <http://portal.mec.gov.br/cne/arquivos/pdf/rces01_01.pdf>. Acesso em: outubro, 2009.

MOORE, Michael; KEARSLEY, Greg. Educação a Distância: Uma Visão Integrada. São Paulo: Thomson Learning, 2007.

ROCHA-PINTO, Sandra Regina. Dimensões Funcionais da Gestão de Pessoas. 8. ed. Rio de Janeiro: Editora FGV, 2006.

THOMPSON, Arthur; STRICKLAND III, A. J. Planejamento Estratégico: elaboração, implementação e execução. São Paulo: Pioneira, 2000.

TORREZAN, Cristina; BEHAR, Patrícia Alejandra. Parâmetros para a construção de materiais educacionais digitais do ponto de vista do design pedagógico. In: Modelos Pedagógicos em Educação a Distância. Patrícia Alejandra Behar (org). Porto Alegre: Artmed, 2009. 